\title{
Dynamics of Seafloor Processes Advances from Benthic Observing Technologies
}

BY DEBORAH B. JAHNKE AND RICHARD A. JAHNKE

INTERACTIONS WITH the seafloor are a controlling characteristic of coastal environments, resulting in unique and intensified processes that define the coastal ecosystem (Figure 1). At the most fundamental level, it is the presence of the seafloor that differentiates continental margin ecosystems from their oceanic counterparts. For example, friction with the bottom controls internal-wave and current-generated turbulence; solute exchange across the sediment-water interface impacts geochemical cycles, nutrient inputs, and biological production; and sediment resuspension and bedload transport are important pathways for estuarine-shelf and shelf-ocean material exchange. It has long been recognized that well-defined thresholds control sediment resuspension and transport where rare, energetic events dominate over mean conditions. Recent measurements revealed that most of the processes depicted in Figure 1 vary dynamically over a broad spectrum of temporal and spatial scales. To improve understanding of coastal dynamics, sensing systems are needed that provide benthic observations at relevant scales.

Coastal oceanographic research is rapidly advancing by twenty-first century augmentation of expeditionary research with real-time, remote observations that facilitate data acquisition on a wider range of spatial and temporal scales than achieved previously, reduce observational bias by providing continuous, high-resolution measurements, and promote shipbased research by directing sampling activities to specific targets and features. However, most emergent remote-sensing technologies, such as satellite-mounted sensors and shore-based high-frequency (HF) radar arrays, focus on the sea surface. A comprehensive understanding of the coastal benthic boundary layer (BBL) will not come from existing remote sensing, or from the study of isolated processes in this complex environment. Rather, the physics, geology, chemistry, and biology must be interpreted holistically, in situ, and over process- appropriate length and time scales.

Coastal Benthic Exchange Dynamics (CBED), CoOP's final initiative, was undertaken to promote the development and implementation of BBL observing technologies by coupling engineering development to focused studies of BBL processes. Four individual projects that incorporate a variety of sensor technologies are currently underway in contrasting benthic environments. The integrative Benthic Exchange Dynamics (iBED) project is designed to fundamentally advance the study of solute fluxes across the sediment-water interface through further development and commercialization of BBL eddy correlation technologies. Although currently limited to only a few solutes for which rapidly responding sensors are available, this technique is particularly promising because it can be applied to environments that cannot be studied with traditional techniques and because it provides a nonintrusive method for estimating fluxes. The Multidisciplinary Benthic 


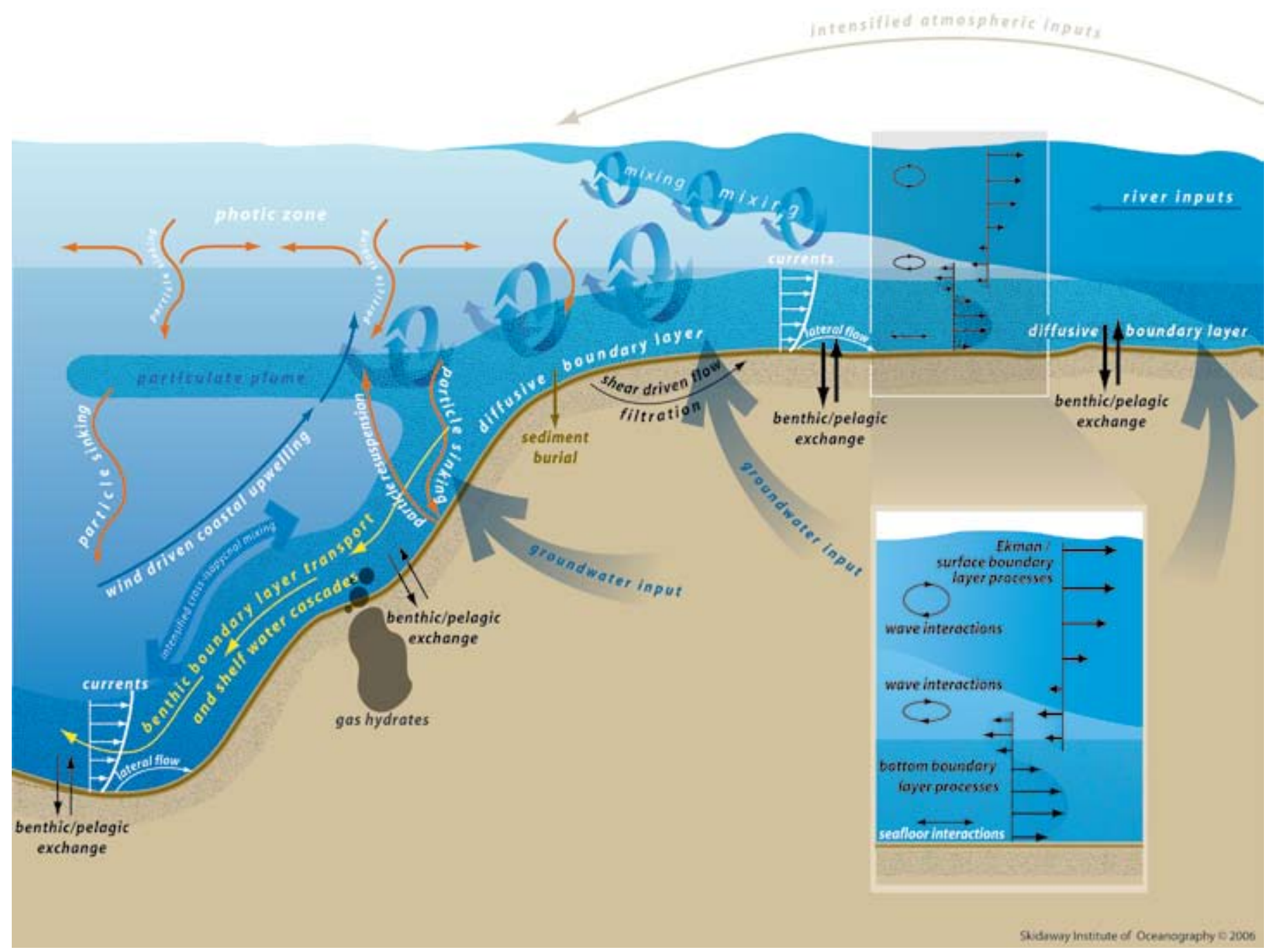

Figure 1. Schematic of important transport and exchange processes that control the characteristics, dynamics, and mass transfer across and within the continental margin system. This representation is not exhaustive and places emphasis on interactions with the seafloor, for at the most fundamental level, it is the presence of the seafloor that differentiates the margin ecosystem from its oceanic counterpart.

Exchange Dynamics (MUDBED) project has installed BBL observing platforms in a dynamic, muddy estuarine environment. Applying new analysis techniques, the evolution of suspended and seabed sediments following energetic resuspension and deposition events can now be tracked in real time, directing scientists to undertake detailed benthic sampling at the time scales needed to evaluate perturbation events. The Kilo Nalu project builds on a nearshore reef observatory on the southern coast of Oahu, Hawaii, to examine seabed-water column dynamics in a wave-dominated coastal system exposed to oceanic forcing. Supported by a seafloor cable supplying power and communications, innovative instrumentation to measure wave boundary layers and resulting pore water exchanges in this physically complex environment have been deployed. In contrast, the Benthic Observatory and Technology Testbed on the MidShelf-Understanding Processes (BOTTOMS-UP) project has installed benthic observing technologies on the Georgia shelf to examine the forcing and resulting dynamics of seafloor solute and particle exchange on a broad, continental shelf with sediments of elevated permeability. These projects are currently completing their final field campaigns, so a comprehensive synthesis of results and observations is not yet possible. The following shorter articles provide highlights of CBED discoveries and technical accomplishments to date that demonstrate both realized and incipient capabilities of seafloor observatories. 四

Deborah B. Jahnke (deb.jahnke@ skio.usg.edu) is Research Coordinator and CoOP Office Manager, Skidaway Institute of Oceanography, Savannah, GA, USA. Richard A. Jahnke is Professor, Skidaway Institute of Oceanography, Savannah, GA, USA. 